\title{
Complexidade na Física e seu Ensino: Apresentação da Edição Especial
}

\author{
Complexity in Physics and Physical Education: Presentation of the Special Edition \\ Nelson Studart*10 \\ ${ }^{1}$ Universidade Federal de São Carlos, São Carlos, SP, Brasil.
}

Recebido em 25 de janeiro de 2021. Aceito em 25 de janeiro de 2021.

\begin{abstract}
Este artigo descreve os 18 artigos e um texto suplementar que compõem a Edição Especial da RBEF sobre a Complexidade na Física e seu Ensino. Nessa edição são abordados temas abrangentes que, de algum modo, contemplam visões diferentes da complexidade por físicos e pesquisadores da ciência da complexidade. Alguns tópicos se enquadram na tradicional física dos sistemas complexos, mas outros extrapolam a área da Física, embora com a atuação de físicos, e são estudados em vários e diferentes campos do conhecimento. São incluídos nessa edição estudos de assuntos complicados, intrincados, que, embora não sejam categorizados como parte da ciência da complexidade, demandam novas abordagens teóricas e métodos experimentais desafiadores. Essa apresentação contém discussões breves do conceito de emergência em contraponto ao de reducionismo, de caos quântico, complexidade na Astrofísica, estudos da mente, física estatística não extensiva, modelos epidemiológicos, migração celular, materiais complexos, escoamentos turbulentos, modelagem computacional, neuroeducação, além da complexidade e dos desafios no Ensino de Física.
\end{abstract}

Palavras-chaves: Sistemas complexos, ciência da complexidade, ensino de física.

This article describes the 18 articles and a supplementary text of the RBEF Special Edition on Complexity in Physics and Physics Teaching. They are comprehensive texts that, in some way, contemplate different views of researchers of the science of complexity. A few ones fit into the traditional physics of complex systems and others that extrapolate the area of Physics, although physicists are working on these topics, and they are studied in several and different fields of knowledge. Included in this Edition are studies of complicated, intricate subjects, which, although not classified as part of the science of complexity, demand new theoretical approaches and challenging experimental methods. This article presents a brief discussion of the concept of emergency as opposed to that of reductionism, quantum chaos, complexity in Astrophysics, studies of the mind, non-extensive statistical physics, epidemiological models, cell migration, complex materials, turbulent flows, computational modeling, neuroeducation, and the complexity and challenges in Physics Education.

Keywords: Complex systems, science of complexity, physics teaching.

\section{Introdução}

Esta edição especial "Complexidade na Física e seu Ensino" aborda, de um lado, os sistemas complexos, que, do ponto de vista do físico, são geralmente aqueles relacionados aos fenômenos não-lineares e a sistemas com dependência crucial das condições iniciais de contorno. No entanto, sistemas complexos extrapolam a área da Física, embora os físicos estejam atuando nela, e são estudados em vários e diferentes campos de pesquisa.

De outro lado, essa edição contempla uma noção mais abrangente de complexidade de modo a incluir alguns assuntos complicados, intrincados, que, embora não sejam categorizados como parte da "Ciência da Complexidade", demandam novas abordagens teóricas e métodos experimentais desafiadores na Física e seu Ensino.

"Complexidade" tem sido definida de muitas maneiras durante décadas e a palavra tem expressado tanto

\footnotetext{
* Endereço de correspondência: n.studart@gmail.com
}

sistemas e problemas complexos como aqueles complicados ${ }^{1}$ Por exemplo, em ciências humanas, o sociólogo Roberto Poli destaca que:

Os problemas complicados se originam de causas que podem ser distinguidas individualmente; eles podem ser endereçados peça por peça; para cada entrada do sistema, há uma saída proporcional; os sistemas relevantes podem ser controlados e os problemas que apresentam permitem soluções permanentes. Por outro lado, problemas e sistemas complexos resultam de redes de múltiplas interações que não podem ser distinguidas individualmente; devem ser tratados como sistemas inteiros, isto é, eles não podem ser tratados de forma fragmentada; eles são tais

\footnotetext{
${ }^{1}$ Pode-se obviamente haver sistemas "simples" que são fáceis de entender e resolver.
} 
que pequenas entradas podem resultar em efeitos desproporcionais; os problemas que eles apresentam não podem ser resolvidos de uma vez por todas, mas precisam ser gerenciados sistematicamente e, normalmente, qualquer intervenção gera novos problemas como resultado das intervenções que os tratam; e os sistemas relevantes não podem ser controlados - o melhor que se pode fazer é influenciá-los, aprender a "dançar com eles", como Donella Meadows ${ }^{2}$ disse acertadamente [1].

A cientista de computação, Michele Mitchell, adota uma definição que está mais próxima do consenso na área no livro Complexity: a guide tour. Um sistema complexo é:

Um sistema em que grandes networks de componentes com nenhum controle central e regras simples de operação dão origem a comportamento coletivo complexo, processamento de informação sofisticado e adaptaçã ${ }^{3}$ por meio de aprendizagem ou evolução [2].

Já o físico Giorgio Parisi adota uma definição simples: "um sistema é complexo se seu comportamento depende de forma crucial dos detalhes do sistema" [3]. No caso de fenômenos físicos, o "dançar com eles" corresponderia à possibilidade de ainda fazer predições sobre o comportamento do sistema complexo, sujeito a influências externas, mas essas predições agora teriam natureza probabilística.

A complexidade em ciência remonta aos estudos, por Jacques Hadamard (1865-1963) e Henri Poincaré (1854-1912), ao final do século XIX, de certas classes de sistemas cuja evolução dinâmica depende de forma hipersensível das condições iniciais e exibiam tanto determinismo quanto imprevisibilidade a longo prazo. 4

O grande físico e matemático Pierre Simon de Laplace (1724-1827) no Ensaio Filosófico sobre Probabilidades assume a "previsibilidade" de qualquer sistema de muitas partículas, no sentido de que as posições e velocidades instantâneas podem ser calculadas, desde que sejam conhecidas as equações do movimento e as condições iniciais.

${ }^{2}$ A cientista ambiental Donella Meadows no artigo "The Dance": "We thought that [through systems thinking] we could control systems. That we could make systems do what we wanted them to do. But we found out: we can't control systems or figure them out. But we can dance with them! (shorturl.at/mGI34).

${ }^{3}$ Existem, é evidente, sistemas complexos não adaptativos, como os furacões e os fluidos turbulentos, tratados nessa edição.

${ }^{4}$ Hadamard mostrou a dependência hipersensível das condições iniciais para um tipo de bilhar retorcido em que a superfície da mesa é curva. Poincaré examinou a dinâmica de um gás de esferas elásticas e a meteorologia para justificar uma descrição probabilística [4].
Devemos considerar o estado presente do universo como efeito dos seus estados passados e como causa dos que se vão seguir. Suponha-se uma inteligência que pudesse conhecer todas as forças pelas quais a natureza é animada e o estado em um instante de todos os objetos - uma inteligência suficientemente grande que pudesse submeter todos esses dados à análise -, ela englobaria na mesma fórmula os movimentos dos maiores corpos do universo e também dos menores átomos: nada lhe seria incerto e o futuro, assim como o passado, estaria presente ante os seus olhos (Laplace na Ref. [5]).

No caso da Física Clássica, a noção de previsibilidade mudou pela compreensão do caos determinístico, haja vista que se mostrou a impossibilidade de previsões de longo prazo em sistemas dinâmicos $5^{5}$ Pequenas mudanças nas condições iniciais acarretam enormes mudanças no resultado final. O advento da Mecânica Estatística considera que estados microscópicos de um sistema de muitas partículas são descritos em termos de probabilidades. As previsões sobre o comportamento do sistema não estão baseadas nas trajetórias das partículas e as grandezas observáveis são expressas em termos de valores médios, variâncias, etc.

Na Mecânica Quântica, embora descrita por equações deterministas, o conceito de trajetória perde o sentido e a "previsibilidade" mesmo para um estado de uma partícula tem natureza probabilística: envolvem valores médios de observáveis.

O que caracteriza sistemas complexos, pelo menos entre os sistemas mais conhecidos, é que as interações entre partículas (ou, os estados) dependem do tempo, como vamos discutir logo em seguida.

É bem conhecido que sistemas longe do equilíbrio formam estruturas complexas dissipativas, assim chamadas por Ilya Prigogine [1917-2003], que podem crescer rapidamente com o tempo. A dinâmica de sistemas fora do equilíbrio pode impulsionar a emergência de fenômenos cooperativos ou de auto-organização [6]. Há muitos exemplos de sistemas de muitas partículas que se tornam muito complicados em situações de não equilíbrio.

Muitos sistemas complexos na Natureza apresentam leis de potência universais e distribuições não-gaussianas com caudas longas. Exemplos significativos são a distribuição de magnitudes de terremotos, intensidades de erupções solares e os tamanhos de avalanches neuronais [7]. Sistemas dito complexos de interesse para a Física exibem um comportamento anômalo descrito por leis de potência que independem das peculiaridades

\footnotetext{
${ }^{5}$ A equação de movimento que descreve a evolução desses sistemas é totalmente determinística, não contém termos estocásticos, mas é não linear.
} 
dos constituintes e da forma de interação do sistema e cuja origem pode ser explicada por diferentes e variados mecanismos. Um exemplo típico na Física da Matéria Condensada é dado pelos fenômenos críticos ${ }^{6}$ $\mathrm{Na}$ vizinhança do ponto crítico, um aumento das flutuações fornece um mecanismo para o surgimento de leis de potência universais que governam divergências em vários observáveis termodinâmicos (compressibilidade, susceptibilidade, entre outros), bem como propriedades estruturais (função de correlação de pares) e estatísticas [8]. Vidros de spins são exemplo de um sistema de muitos corpos que a partir de simples ingredientes no nível microscópico, como interação competitiva e desordem, exibem um comportamento complexo no nível macroscópico. Esse sistema mostra a riqueza do ponto de vista conceitual da forma como surge a complexidade; esse modelo pode ser modificado e generalizado para uso em outras disciplinas científicas [9].

Um sumário de destaques dos sistemas complexos, traduzidos do livro Introduction to the Theory of Complex Systems, por Thurner, Hanel, e Klimek, é dado a seguir [10]:

- Sistemas complexos são compostos de muitos elementos, componentes ou partículas. Esses elementos são normalmente descritos por seu estado, como velocidade, posição, idade, rotação, cor, riqueza, massa, forma e assim por diante. Os elementos podem ter componentes estocásticos.

- Os elementos não se limitam às formas físicas da matéria; qualquer coisa que possa interagir e ser descrita por estados pode ser vista como matéria generalizada.

- As interações entre os elementos podem ser específicas. Quem interage com quem, quando, de que forma e com que força é descrito pelas redes de interação.

- As interações não se limitam às quatro forças fundamentais, mas podem ser de um tipo mais complicado. As interações generalizadas não se limitam à troca de bósons de calibre, mas podem ser mediadas por meio da troca de mensagens, objetos, presentes, informações, até mesmo marcadores, e assim por diante.

- Sistemas complexos podem envolver superposições de interações de intensidades semelhantes.

- Os sistemas complexos são frequentemente caóticos no sentido de que dependem fortemente das condições e detalhes iniciais do sistema. As equações de atualização que descrevem a dinâmica por meio de algoritmos geralmente não são lineares.

- Sistemas complexos são frequentemente sistemas dirigidos. Alguns obedecem às leis de conservação, outros não.

\footnotetext{
6 Fenômenos da Astrofísica também exibem leis de potência (ver artigo de Alves-Brito e Cortesi nessa edição).
}

- Sistemas complexos podem exibir uma estrutura de fase rica e ter uma grande variedade de macroestados que muitas vezes não podem ser inferidos das propriedades dos elementos. Isso às vezes é chamado de emergência. As formas simples de emergência, é claro, já estão presentes na física. O espectro do átomo de hidrogênio ou da fase líquida da água são propriedades emergentes das partículas envolvidas e suas interações.

Embora controverso, qual seria o ponto de vista dos físicos acerca de sistemas complexos versus sistemas complicados? É evidente que os sistemas mais complicados em física, em particular os considerados aqui, não são complexos. Mas é verdade que a maioria dos sistemas complexos são complicados.

Essa edição especial traz trabalhos de físicos brasileiros sobre temas da complexidade em sentido amplo que refletem, em parte, as pesquisas da comunidade.

\section{Reducionismo e Emergência}

O reducionismo pode ser entendido com uma posição intelectual que interpreta um sistema complexo como a soma de suas partes. Ou, tenta a explicação de sistemas inteiros em termos de suas partes individuais e constituintes e suas interações.

O reducionismo tem forte tradição na ciência moderna e é adotado por expressiva e qualificada comunidade de físicos, em especial aqueles que atuam na teoria de partículas elementares e física de altas energias. Um notório defensor dessa corrente é Steven Weinberg que no livro "Sonhos de uma Teoria Final" enfatiza:

$$
\begin{aligned}
& \text { "... o ponto comum em todas as ideias do } \\
& \text { reducionismo é um senso de hierarquia, que } \\
& \text { algumas verdades são menos fundamentais } \\
& \text { do que outras às quais elas podem reduzi- } \\
& \text { das, como a química pode ser reduzida à } \\
& \text { física." (Weinberg 1993, citado na Ref. [11]). }
\end{aligned}
$$

No modo extremo de pensar, o reducionista acredita que todos os fenômenos na natureza se reduzem a uma teoria final, a uma teoria de tudo.

Em contraste com a bastante antiga visão reducionista, defendida por Weinberg entre outros, o uso da palavra emergência em Física é um conceito relativamente novo introduzido por Philip Anderson [12] em seminal artigo que teve enorme repercussão na comunidade de físicos e gerou grande polêmica entre os dois. ${ }^{7}$ Anderson

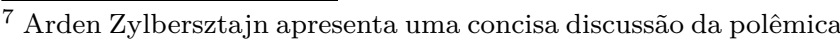
e apresenta resultados sobre a opinião da comunidade de físicos brasileiros sobre o assunto 11. A polêmica entre esses brilhantes físicos teve repercussões importantes além da academia, como o cancelamento pelo congresso americano do financiamento para a continuação das obras do Super Colisor Supercondutor (SSC na sigla em inglês)
} 
apresentou a ideia de que cada nível em nossa hierarquia de compreensão da ciência envolve processos emergentes, e que, além disso, a noção de Física "fundamental" não está vinculada ao nível da hierarquia.

Apesar da diferença entre esses pontos de vista, parece que nenhum deles ignora o outro. Por exemplo, Piers Coleman, que foi estudante de Anderson, defende uma posição conciliatória, e com base em episódios da história da física clássica e quântica afirma que "a emergência se transforma em uma visão reducionista da natureza. Muitas vezes, uma compreensão profunda da física reducionista depende da compreensão de suas consequências emergentes" [13]. Contudo, Anderson acredita em um programa emergentista no futuro imediato [14]:

as ideias de emergência e reducionismo são simplesmente dois lados da mesma moeda, do ponto de vista filosófico. Mas, é claro que o próximo século $\left[\mathrm{o} 21^{\circ}\right.$ ] será dominado pelo primeiro, uma vez que o programa reducionista está quase completo, e uma vez que a maioria dos problemas interessantes estão no lado complexo das hierarquias.

Uma abordagem mais filosófica dessa questão pode ser vista no trabalho de Martínez, Garcia e Bernal [15].

Peter Schulz discute nessa edição o manifesto de Philip Anderson More is different [12, e sua importância para a defesa da complexidade como um tema em oposição ao reducionismo, bem como de sua hierarquia das ciências.

\section{Sistemas Complexos versus Sistemas Complicados}

Nesta seção, a visão dos autores Holovatch, Kenna e Thurner, apresentada a seguir, pode ajudar a esclarecer a distinção entre sistemas complicados e sistemas complexos [16].

Considere uma network ou rede regular de nós ou entidades (spins, agentes, etc.) conectadas por meio de vínculos (interações). Cada nó pode ser caracterizado por um dos possíveis estados do sistema descritos por um objeto matemático (ex. escalar, vetor, matriz). Uma configuração singular de todos os nós é um microestado e o estado do sistema total é o macroestado. Se $\sigma_{i}$ denota o estado de um nó, sua evolução pode ser descrita por um sistema de equações

$$
\frac{d \sigma_{i}}{d t}=F\left(\left\{\sigma_{i}(t)\right\}, \boldsymbol{M}\right), \quad i=1, \ldots, N,
$$

em que $N$ é o número de agentes, $\boldsymbol{M}$ é a matriz de interação com elementos $M_{i j}^{\alpha}$ que varrem todos os pares de agentes e $\alpha$ refere-se a todos os possíveis tipos de interações. Caso $F$ seja uma função determinística, as soluções da Eq. (1) são unicamente determinadas pela matriz de interação e as condições iniciais $\sigma_{i}(0)$ para todo $i$. As equações podem ser complicadas, mas, em princípio, podem ser tratadas analiticamente. Deve-se assinalar que métodos da física estatística são aplicados quando o número de agentes $N$ é muito grande. Tais sistemas são "complicados", mas não se enquadram na categoria dos complexos.

No caso da ciência dos sistemas complexos, a dinâmica dos microestados (nós) e das interações são mutuamente dependentes. A evolução do sistema é descrita por um sistema de equações

$$
\begin{aligned}
\frac{d \sigma_{i}}{d t} & =F\left(\left\{\sigma_{i}(t)\right\}, \boldsymbol{M}(t)\right), \quad i=1, \ldots, N, \\
\frac{d M_{i j}^{\alpha}}{d t} & =G\left(\left\{\sigma_{i}(t)\right\}, \boldsymbol{M}(t)\right), \quad i<j=1, \ldots, N .
\end{aligned}
$$

A questão da complexidade se manifesta na dependência temporal das interações; como as "condições iniciais" não podem ser fixadas, soluções analíticas ou numéricas do sistema de Eqs. (2) e (3) não são possíveis. Mas é possível, felizmente, reduzir as Eqs. (2) e (3) para o sistema de Eq. (1) quando os processos dinâmicos governados pelo sistema de Eqs. (2) e (3) acontecem em diferentes escalas de tempo. Contudo, resta o dilema de causalidade: são as interações que definem os estados, ou vice-versa?

Os processos descritos pelas Eqs. (2) e (3) não seguem uma dinâmica analítica (solução de equações de movimento), mas sim uma dinâmica algorítmica. Pode-se concluir que "a física é geralmente analítica, os sistemas complexos são algorítmicos. As previsões quantitativas que podem ser testadas experimentalmente podem ser feitas dentro do paradigma analítico ou algorítmico" 10.

Mas pode existir comportamento complexo, no caso caótico, em sistemas determinísticos modelados pela Eq. (1). O pioneirismo do estudo de tais sistemas pode ser atribuído, em grande parte, a Henri Poincaré (18541912). A análise do desafiador problema de $n$ corpos, discutido desde Newton por notáveis matemáticos e filósofos da ciência, com implicações à estabilidade do sistema solar lhe valeu o prêmio por ocasião do sexagésimo aniversário do Rei da Suécia em 1889.8 Embora não tivesse à disposição as atuais ferramentas matemáticas e computacionais, introduziu métodos geométricos, topológicos e probabilísticos, bem como teceu considerações filosóficas, para, de modo qualitativo, entender o comportamento extremamente complicado de muitas soluções desse problema. Poincaré mostrou que o problema de três corpos não poderia ser resolvido quantitativamente pela dinâmica hamiltoniana, e a partir dessa descoberta surgiu a teoria dos sistemas dinâmicos. Além de mostrar que o problema dos n-corpos não poderia ser resolvido analiticamente, Poincaré descobriu a primeira manifestação do comportamento caótico na

\footnotetext{
8 Rei Oscar II ofereceu um prêmio substancial e uma medalha para a primeira pessoa a obter uma solução geral do problema de $n$-corpos. Poincaré ganhou o prêmio pela análise do problema de três corpos. Ver ensaio primoroso de Poincaré na Ref. [17.
} 
forma de emaranhados homoclínicos, mostrando que aleatoriedade e determinismo se tornam compatíveis por causa da imprevisibilidade a longo prazo. Com esse estudo, tornou-se a primeira pessoa a propor a possibilidade de caos em um sistema determinístico, no caso o sistema solar, lançando as bases da teoria moderna da dinâmica caótica desenvolvida a partir da década de 1960.

\section{Gato e a Borboleta}

É conveniente retomar as ideias de Poincaré numa linguagem moderna. Para isso, considere a evolução determinística de um modelo idealizado descrita pela Eq. (1) com notação simplificada [18

$$
\dot{x}(t)=F(\{x(t)\}),
$$

em que $F$ é uma função diferenciável. É bem conhecido do determinismo defendido por Laplace, por exemplo, de nossa experiência no estudo da Mecânica Clássica que a previsibilidade infinita do futuro do sistema é bem determinada pelo seu estado inicial. Na verdade, se o estado inicial é conhecido com alguma imprecisão $\Delta x(0)$, o erro correspondente evolui na forma $\Delta x(t) \propto$ $e^{\lambda t} \Delta x(0)$, em que $\lambda$ é o expoente de Lyapunov. Quando $\lambda>0$, a evolução é dita caótica, e sua previsibilidade é obviamente limitada a algumas vezes $\lambda^{-1}$. Atualmente sabe-se que certos sistemas seguem uma dinâmica determinística e são caóticos. Por exemplo, no caso do sistema solar, o valor estimado do expoente de Lyapunov $\lambda \approx(5 M \text {.anos })^{-1}$, e o tempo de Lyapunov para os planetas internos varia de 4-5 milhões de anos [19].

Assim, apesar da aparente simplicidade da Eq. (4), sua solução pode depender de modo ultrassensível das condições iniciais, caracterizando-os na categoria dos sistemas complexos. Recomenda-se a leitura do artigo de revisão introdutório sobre a teoria do caos determinístico, de Cattani, Caldas e colaboradores [20].

A teoria dos sistemas dinâmicos acarretou uma mudança drástica em relação ao determinismo na ciência, assim como a Mecânica Quântica provocou uma revolução ao introduzir probabilidade intrínseca na descrição do mundo microscópico. O estudo do caos quântico, iniciado de forma mais rigorosa por Martin Gutzwiller em 1971 [21], é uma tentativa de descrever coerentemente sistemas em que tanto a Mecânica Quântica quanto a dinâmica não-linear são relevantes. Ou seja, estender as noções do caos clássico ao regime quântico [22].

Esta edição traz artigo de Marcel Novaes sobre caos quântico que teve uma contribuição pioneira de Einstein em 1917 [23] e que tem sido pesquisado com mais empenho em tempos recentes a partir dos trabalhos de Gutzwiller e Sir Michael Berry, e do uso de matrizes aleatórias a partir da década de 80. Novaes escolheu as abordagens do caos quântico relacionadas com sua pesquisa (o campo é vasto) via teoria de matrizes aleatórias e aproximação semiclássica. Esses métodos são complementares, com uso dependendo do problema a ser tratado. É importante destacar a realização de caos quântico no comportamento de elétrons em nanoestruturas semicondutoras e em nanotubos de carbono [24.

\section{Astrofísica Complexa e Bela}

A Astrofísica é um ramo da Física e Astronomia que segue no século XXI como uma das mais fascinantes ciências básicas. A relatividade geral, de extrema importância para descrever fenômenos astrofísicos e a estrutura e evolução do Universo, certamente pode ser incluída na classe de sistemas complexos descrita na seção 3: a dinâmica dos agentes (suas trajetórias no espaço) se desdobra conforme a Eq. (2) para um espaço fixo $\mathrm{M}$, porém em função da dinâmica, o espaço $\mathrm{M}$ muda de acordo com a Eq. (3). Por outro lado, a Astrofísica fornece exemplos que preenchem os objetivos da presente edição de sistemas complicados versus complexos, como enfatizado no artigo de Alves-Brito e Cortesi:

Além disso, muitos sistemas físicos estudados em Astrofísica são complicados, o que é diferente de complexo, envolvendo inúmeros processos (astro)físicos que operam num grande intervalo de escalas físicas e temporais, ou seja, sistemas descritos de maneira direta e limitada por um conjunto de equações não lineares, o que nos impede, em primeira aproximação, de tratá-los como sistemas simples. Isso implica em dizer que quase todos os grandes problemas dinâmicos da Astrofísica Contemporânea, sobretudo aqueles ligados à cosmologia, formação e evolução química de galáxias, formação e dinâmica de sistemas galácticos e planetários, entre outros, exigem cálculos massivos de simulação numérica e computacional, que envolvem matemática, um vasto conjunto de observação e processamento de dados e aplicação de leis físicas, o que caracteriza, parcialmente nesse artigo, a expressão sistemas complexos.

Os autores justificam a complexidade da Astrofísica pela enorme quantidade de dados obtidos por telescópios, variedade de padrões e comportamentos complexos, e a necessidade de tratamento algorítmico para lidar com big data e modelos computacionais sofisticados devido às interações não lineares.

$\mathrm{O}$ artigo revisa de forma didática as abordagens teóricas e metodológicas da Física e Matemática relevantes para a Astrofísica e Astronomia e descreve em detalhes fenômenos incríveis do Cosmos; formação e evolução dos principais tipos galácticos; estrutura dinâmica complexa do par "Antena" de galáxias, mostrada na Figura 1, cuja compreensão exige modelos 


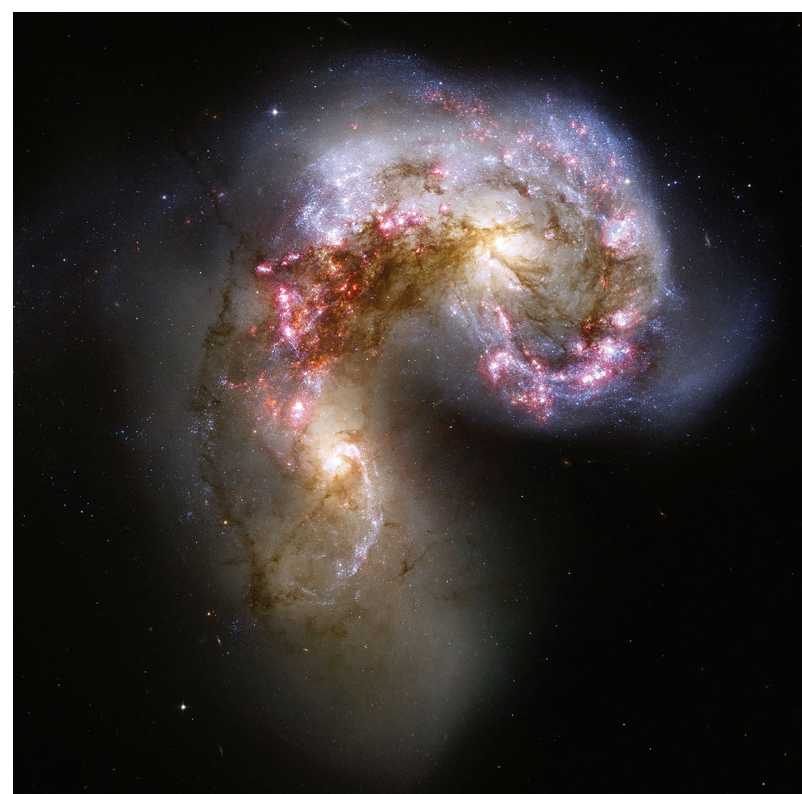

Figura 1: Belo e famoso flagrante de canibalismo galáctico no Universo, das galáxias NGC 4038 e NGC 4039, conhecido como "par Antena". Fonte: Alves-Brito e Cortesi (artigo nessa edição).

"top-down; caos nos sistemas gravitacionais; e a evolução químico-dinâmica da Via Láctea.

\section{Materiais e Fluidos Complexos}

\section{- Descoberta e design de materiais}

Os avanços no processamento têm permitido a fabricação de materiais, novos ou modificados, que exibem estruturas muito mais complexas do que as antes estudadas. Mesmo materiais conhecidos passaram a exibir novas e, algumas inesperadas, propriedades quando foi melhorada a capacidade de processamento. Esforço tem sido dispendido para desenhar novas estruturas que possuam as propriedades requeridas com determinados objetivos na sua produção.

A combinação de métodos computacionais, em especial, a teoria de funcional de densidade, simulações de Monte Carlo e dinâmica molecular, associados a experimentos, permitiu a geração de uma quantidade enorme de dados que tem permitido o uso de métodos de Aprendizado de Máquina em Física, Química e Ciência de Materiais. Nessa última área, o aumento contínuo de poder computacional e desenvolvimento de códigos mais eficientes contribuíram para o design de grandes grupos de materiais, de modo a selecionar os candidatos experimentais ideais [25]. Aprendizado de máquina (Machine Learning) é um subconjunto da Inteligência Artificial9 que visa a "aprender", a partir de exemplos

9 Segundo o Dicionário Oxford, o estudo e desenvolvimento de sistemas de computador que podem copiar o comportamento humano inteligente. Em suma, como fazer computador pensar como gente. ou de experiência anterior, e a ser capaz de simular tarefas específicas "inteligentes". O método tem sido aplicado a uma grande variedade de sistemas artificiais e naturais 26 .

Gabriel R. Schleder e Adalberto Fazzio trazem uma revisão ampla e didática do método de aprendizado de máquina, enfatizando a descoberta, design e optimização de materiais quânticos. Dois exemplos ilustrativos são explorados com diferentes níveis de aprendizado: "exploração do espaço fase de materiais, tanto atômico como configuracional, na descoberta e design de novos materiais bidimensionais (2D); descoberta de novas estruturas hipotéticas e/ou desconhecidas por otimização global no espaço configuracional, na busca e predição de estruturas de materiais usando potenciais atomísticos aprendidos por ML." Os autores manifestam seu entusiasmo quanto ao uso de aprendizado de máquina na área de materiais avançados reproduzindo citação conhecida de pesquisador da área que prevê que "o aprendizado de máquina não vai substituir os cientistas, mas os cientistas que usam aprendizado vão substituir os que não usam".

\section{- A vida dura do osso}

Um campo de fronteira na Ciência dos Materiais são os materiais bioinspirados que reproduzem princípios de design de materiais naturais como ossos, dentes, plantas e conchas de moluscos [27]. O osso é um fascinante material compósito que combina a natureza de um tecido biológico vivo com propriedades mecânicas (dureza e tenacidade) surpreendentes tendo em vista a fragilidade de seus componentes químicos.

Nesta edição especial, o grupo de André Studart revisa descobertas científicas que evidenciam o osso como um sistema complexo, pois exibe propriedades que emergem das interações mediadas por células, partículas e moléculas em múltiplas escalas de comprimento. Essas interações levam à auto-organização, guiada pelas atividades das células vivas, estruturas hierárquicas das fases inorgânica (hidroxiapatita) e orgânica (colágeno), e comportamento adaptativo a estímulos mecânicos externos sem a necessidade de uma unidade de controle central. Além da capacidade de auto-organização característica de sistemas complexos, estudos recentes demonstram a importância de processos estocásticos na formação do osso 28. Sendo um sistema biológico, as células do osso também apresentam compartimentos intracelulares possivelmente gerados por processos biofísicos de separação de fase induzidos pelo metabolismo celular [29]. Essas descobertas têm atraído a comunidade de físicos para o estudo de sistemas biológicos e apresentam novas oportunidades para pesquisa em materiais complexos como o osso.

O artigo se caracteriza por exposição didática primorosa e a introdução de boxes tutoriais possibilita ao leitor pouco familiar a base necessária para a compreensão dos temas abordados. Além disso, é ricamente ilustrado com figuras bem elaboradas. Na Figura 2 são apresentados os elementos que caracterizam a complexidade do osso. 


\section{Auto-organização}

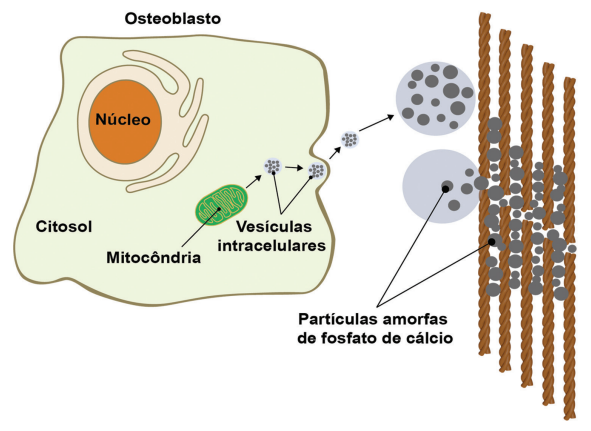

\section{Comportamento adaptativo}

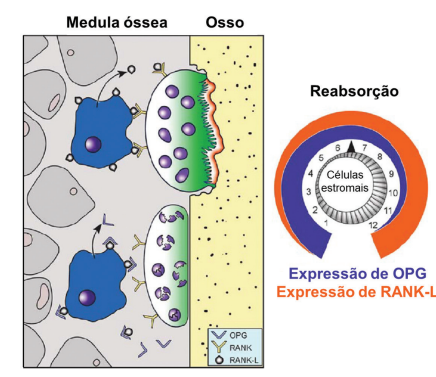

\section{Estrutura hierárquica}

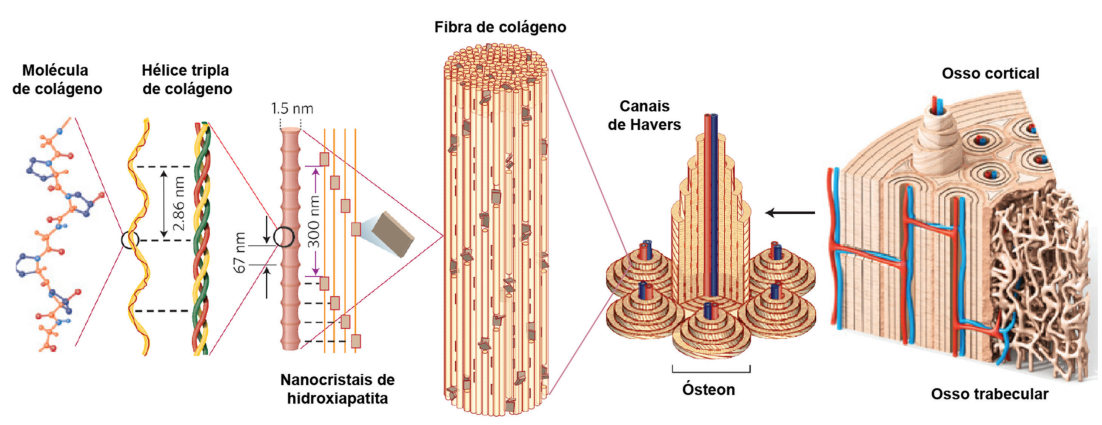

Figura 2: Elementos da complexidade no osso. Fonte: Magrini et al. (artigo nessa edição).

(a)

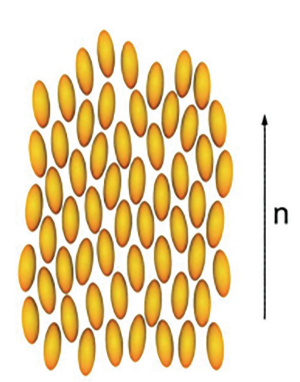

A

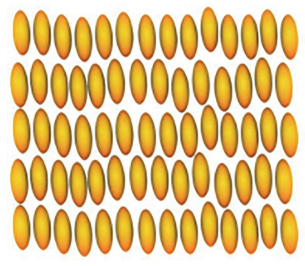

(b)

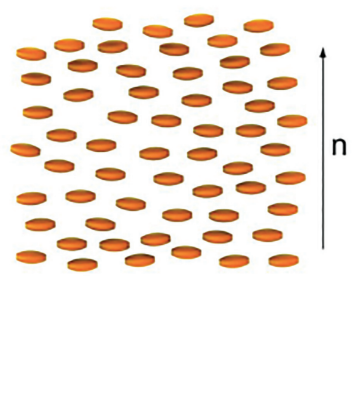

C

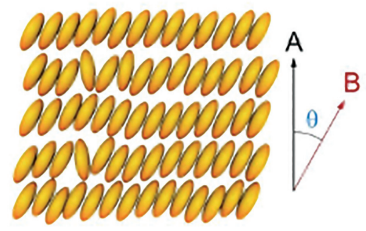

(c)
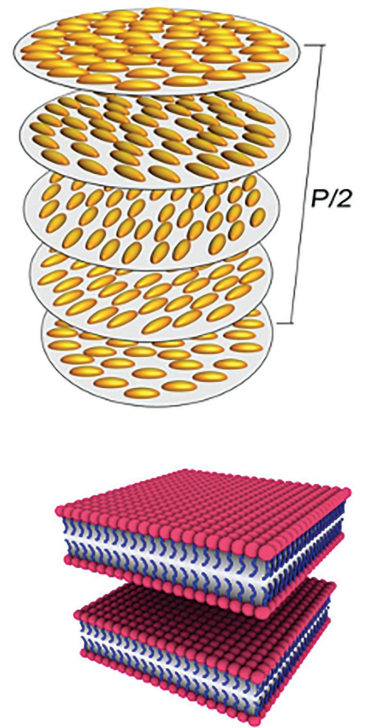

(e)

Figura 3: Moléculas ordenadas: na fase nemática uniaxial, (a) calamítica e (b) discótica; (c) Estrutura da fase colestérica; (d) fases esméticas A e C; (e) Cristal líquido liotrópico na fase lamelar, agregados de moléculas anfifílicas. Fonte: Figueiredo (artigo nessa edição).

\section{- Líquidos ou sólidos? "Cristais líquidos"}

Não é uma coisa nem outra. O termo "cristal líquido" designa um estado em que a matéria pode se apresentar, um estado intermediário entre o estado sólido cristalino e o estado líquido isotrópico. Antonio Figueiredo descreve as propriedades gerais e aplicações dessa importante classe de materiais. Os principais tipos e estruturas dos cristais líquidos e seus diagramas de fases são criteriosamente descritos. A Figura 3 mostra o ordenamento de moléculas em algumas estruturas citadas no artigo. 


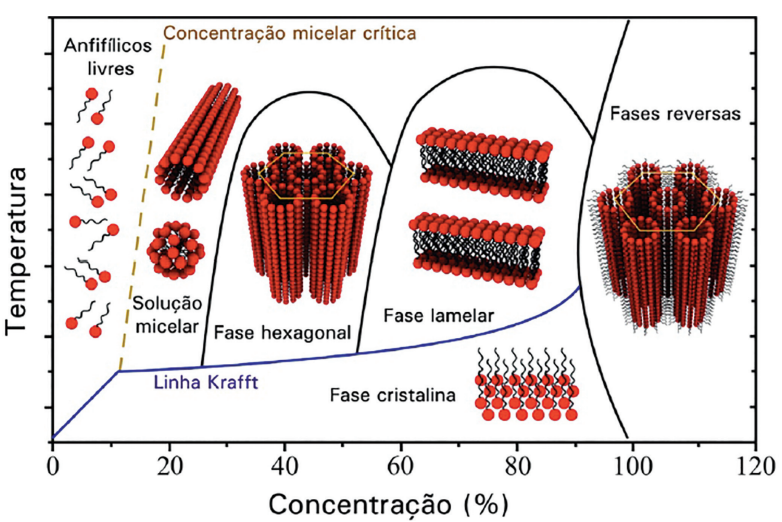

Figura 4: Representação esquemática de diagrama de fases de mistura liotrópica binária (moléculas anfifílicas e água): temperatura em função da concentração de anfifílicos. Fonte: Figueiredo (artigo nessa edição).

Várias estruturas investigadas no artigo são típicas de cristais liotrópicos que apresentam várias outras fases, além da lamelar da Figura 3(e). Apresentam um rico diagrama de fases como mostrado na Figura 4

Maior aprofundamento nas discussões é dedicado à descrição das fases nemáticas, uniaxiais e biaxial, tanto do ponto de vista experimental quanto teórico. A escolha se deve ao fato de que os materiais que exibem a mesofase nemática biaxial se constituem no único exemplo na natureza em que a substância líquida tem três índices de refração diferentes. Apesar de estudada há tempo, ainda coloca questões fundamentais na área de fluidos complexos.

As várias estruturas espaciais ordenadas dos constituintes dos cristais líquidos possibilitam o seu uso na fabricação de dispositivos magneto e eletro-ópticos com características únicas.

O artigo aborda os tópicos mais relevantes dessa fascinante área de cristais líquidos, e uma leitura atenta trará grandes benefícios para quem quer se familiarizar ou se atualizar com o desenvolvimento recente dessa área.

\section{Física Estatística}

\section{- Do claustro ao confinamento epidêmico}

Um exemplo clássico é a propagação de epidemia no tradicional modelo SIR em que, segundo a abordagem na seção 3 os indivíduos estão em três possíveis estados: suscetíveis, infectados e recuperados com imunidade. As interações entre os indivíduos são diferentes dependendo de seus estados: se infectado encontra-se com recuperado, a interação é: vírus é transmitido, enquanto se dois infectados se encontram, nada acontece, nenhuma interação (e nenhuma mudança de estado).

Paulo Murilo de Oliveira estuda, usando uma versão espacial do modelo SIR, a propagação de epidemias por meio de simulação computacional num sistema em que parte da população se mantém confinada em claustros e a outra parte circula pelas ruas. O índice de confi- namento é a fração confinada da população. Diferentes quantidades são medidas em função deste índice, para uma população total fixa, mostrando a existência de transições de fase dinâmicas.

O objetivo é investigar tais transições à luz do tradicional campo de estudos das transições de fase e fenômenos críticos. Este campo de estudos é o "pai" dos hoje chamados sistemas complexos, estudados com os mesmos métodos que os físicos aplicam ao campo "pai", muitas vezes pelos mesmos físicos, além de acadêmicos de outras áreas que se incorporaram ao novo campo.

Embora o modelo não seja capaz de fazer previsões quantitativas para epidemias reais, ele exibe transições de fases dinâmicas. Para complementação do atual estudo, recomenda-se a leitura do artigo de Tânia Tomé e Mário de Oliveira, publicado nesta revista, em que é feita uma análise de seis modelos determinísticos de propagação epidêmica [30].

No momento da pandemia da Covid-19, esse artigo é bastante atual e oportuno e ressalta a relevância da ciência no enfrentamento da crise com as ferramentas que cada área dispõe. A comunidade científica brasileira se fez presente com pesquisas baseadas em modelos simples como o usado nesse estudo e em modelos epidemiológicos sofisticados obtendo previsões mais realistas.

O texto completo de Paulo Murilo de Oliveira, dirigido primordialmente para alunos de pós-graduação em física, pode ser encontrado como "Texto Suplementar" no presente artigo.

\section{- O cérebro sob influência de psicodélicos}

O físico e historiador David Kaiser conta no livro How the Hippies Saved Physics que a excitante ciência da informação quântica supreendentemente teve um passado psicodélico [31]. Nos anos 70, tempos de contracultura nos Estados Unidos, um pequeno grupo de físicos excêntricos e subempregados abraçou uma linha de pesquisa pouco ortodoxa e especulativa da Física. Eles estudaram a mecânica quântica junto com o misticismo oriental e a leitura psíquica da mente, e as discussões eram feitas enquanto relaxavam em banheiras de hidromassagem. E por mais incrível que possa parecer, o trabalho do grupo no teorema de Bell e no emaranhamento quântico contribuiu para o progresso da teoria da informação quântica.

Depreende-se que o(a)s autore(a)s desse artigo não têm interesse em fundamentos da Física Quântica, mas usam conceitos e métodos da Física Estatística aliados à teoria das redes complexas com o objetivo de responder uma questão essencial da neurociência: Como entender de forma qualitativa e quantitativa os estados mentais de consciência de seres humanos induzidos por substâncias psicodélicas?

Conceitos básicos sobre a conectividade funcional do cérebro humano em larga escala, e sobre a fenomenologia da neurociência aos psicodélicos são apresentados. É dada uma concisa e interessante descrição dos psicodélicos a partir do LSD. 
São revisados alguns estudos que aplicaram ferramentas da física estatística que foram usados para avaliar dados de neuroimageamento de indivíduos sob a influência de psicodélicos; em especial, foram resumidos resultados de estudo feito pelo grupo com indivíduos sob efeito da Ayahuasca.

\section{- Entropias não aditivas em sistemas complexos}

Constantino Tsallis revisa de forma didática sua proposta de generalização da Mecânica Estatística de Boltzmann-Gibbs, que ficou conhecida como Mecânica Estatística Não Extensiva (MENE), ocasionalmente também chamada q-estatística, proposta inicialmente em 1988 32 Vinte anos depois, o autor procedeu a uma análise do desenvolvimento da teoria e suas aplicações [33]. As entropias não aditivas dependem de um índice $q \neq 1$, em contraste com a entropia de Boltzmann-Gibbs-von Neumann-Shannon, que é aditiva, com índice $q=1$.

No âmbito dos sistemas complexos, o autor sustenta que um sistema em que as correlações espaço-temporais entre os graus de liberdades decaem rapidamente (decaimento exponencial no regime assintótico) obedece à MEBG; se as correlações decaem lentamente, como leis de potências no regime assintótico, há uma indicação de que o sistema obedece à MENE. Tsallis assinala:

Assim, num dado contexto, existe uma única maneira de ser linear e muitas maneiras de ser não linear. [...] Trocando em miúdos para nosso contexto: a mecânica estatística de BG é única (e, portanto, paradigmática); as não boltzmannianas são infinitas, sendo a MENE apenas uma destas. Entretanto, por razões que até agora permanecem ilegíveis (até intrigantes) a MENE, suas $q$-exponenciais e suas $q$-Gaussianas [...] que reproduzem para $q=1$, respectivamente as exponenciais e gaussianas que constituem as inconfundíveis impressões digitais da MEBG emergem, como veremos, com surpreendente frequência nos mais diversos sistemas naturais, artificiais e sociais.

A fundamentação básica é brevemente descrita e as diversas aplicações são discutidas no âmbito dos sistemas complexos, sendo aqui destacados alguns dos estudos referentes ao mapa logístico no limiar do caos; sistemas hamiltonianos clássicos; transições de fase; matéria granular; física de altas energias; redes complexas; mecânica quântica não-linear; economia; epidemiologia 10

\section{- Escoamentos turbulentos}

"Quando eu encontrar Deus, vou lhe fazer duas perguntas: por que a relatividade? E por que turbulência? Eu realmente acredito que ele terá uma resposta para

\footnotetext{
10 O leitor interessado deve consultar extensa bibliografia disponível em http://tsallis.cat.cbpf.br/biblio.htm
}

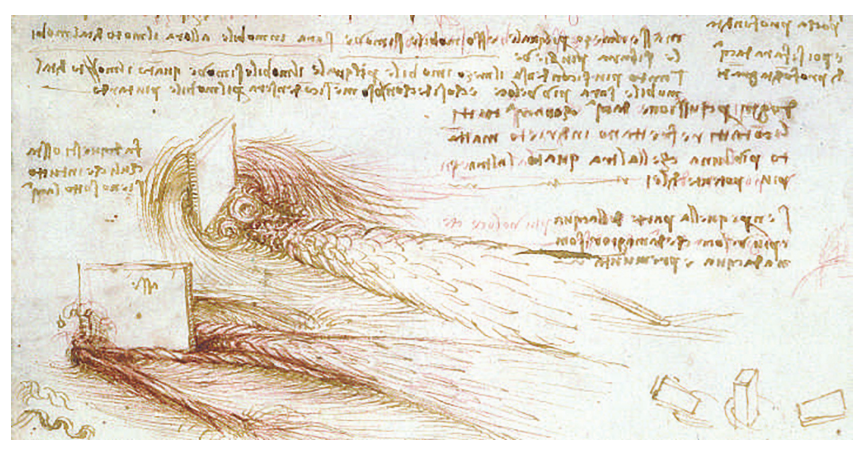

Figura 5: Desenho de Leonardo da Vinci sobre a formação de fluxo caótico da água quando passa por um obstáculo a partir de seus estudos sobre turbulência. Fonte: Ref. [34].

a primeira." A citação apócrifa, atribuída a Werner Heisenberg e repetida ad nauseam, reflete bem o modo como muitos cientistas pensavam sobre a turbulência: um fenômeno há muito observado em que um fluido (líquido ou gás) escoando ordenadamente se desintegra ao transpor um obstáculo em redemoinhos imprevisíveis. A Figura 5 evidencia um dos primeiros estudos da turbulência por Leonardo da Vinci por volta de 1500.

Na mesma linha, Sir Horace Lamb, matemático com trabalhos relevantes em hidrodinâmica, disse em 1932: "quando eu morrer e for para o céu, há dois assuntos sobre os quais espero obter esclarecimento. Um é a eletrodinâmica quântica [EDQ] e o outro é o movimento turbulento dos fluidos. E quanto ao primeiro, estou bastante otimista"11 Seu otimismo se concretizou, no final dos anos 40, com a teoria EDQ proposta por Feynman, Schwinger e Tomonaga. Richard Feynman considerava a turbulência "o mais importante problema não resolvido da física clássica" porque não existe uma descrição do fenômeno a partir de primeiros princípios. Para os iniciantes no campo da turbulência, recomenda-se a leitura descontraída do artigo de Lee Phillips 34 .

O artigo de Luca Moriconi e Rodrigo Pereira pretende mostrar que comentários desse tipo "podem levar à errônea impressão de que a turbulência, ainda que fascinante, seja um campo de investigação árido. Nada mais distante da verdade! De forma semelhante a qualquer outro problema científico aberto em Física, da dinâmica do enovelamento de proteínas à quantização da gravidade, há atividade em ritmo intenso, pontuada por inovações científicas bastante significativas, bem como por um debate permanente sobre quais são as direções mais promissoras da investigação".

O artigo traz uma exposição lúcida e contemporânea sobre a Física Estatística da turbulência. De início, os

\footnotetext{
11 Discurso na Associação Britânica para o Avanço da Ciência. Não confundir com Wills Lamb Jr., ganhador do Prêmio Nobel em 1955, devido à determinação precisa de um surpreendente desvio de energia (Lamb-shift) no espectro do hidrogênio.
} 
autores revisam as noções mais relevantes e consolidadas da dinâmica de fluidos; em seguida, modelos específicos, ainda alvos de debates atuais, são discutidos, exibindo o dinamismo dessa área de pesquisa.

Os autores são bem sucedidos na tarefa de desmistificação das dificuldades na pesquisa de uma área pujante e desafiadora e o artigo vem preencher uma lacuna na literatura lusófona sobre turbulência.

\section{- Processos estocásticos na migração celular}

A migração celular é um processo multifacetado que permite que células individuais e grupos de células se movam e construam ou mantenham tecidos e órgãos para o desenvolvimento embrionário, bem como a regeneração (Ver cartum auto explicativo na Figura 6).

$\mathrm{O}$ artigo de Rita de Almeida trata da modelagem da migração celular. De início, tece considerações gerais sobre modelos e a complexidade associada e afirma que a "complexidade é um conceito útil quando aplicado ao modelo, mais do que ao fenômeno em si. Em fenômenos biológicos, a complexidade do modelo depende do objetivo." A relevância da migração celular é enfatizada, apresentando-se também uma revisão da Biologia. Discute-se o modelo de Langevin, aplicado comumente ao problema da migração celular, e apontase divergência dos dados experimentais com resultados obtidos com o uso desse modelo.

A autora descreve os resultados de seu trabalho usando um modelo teórico anisotrópico que estabelece protocolos de medidas robustas para a comparação com os resultados experimentais obtidos em diferentes montagens e para a tradução para dados obtidos de simulações numéricas.

No final um modelo tridimensional de simulação de migração celular com células extensas é revisto e a complexidade em migração celular é rediscutida.

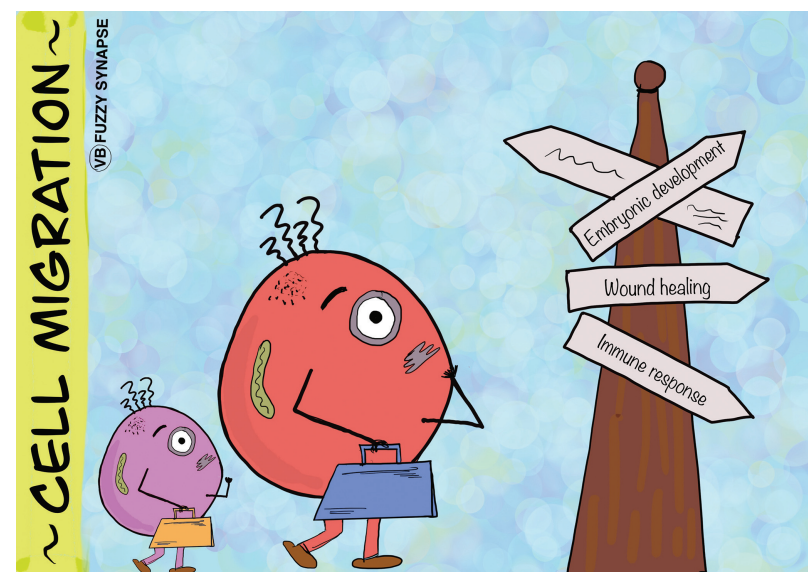

Figura 6: $O$ movimento orquestrado de células (migração celular) torna possível o desenvolvimento embrionário ou cicatrização de feridas ou em qualquer resposta imune. Fonte: fuzzysynapse.com

\section{Ensino de Física: Complexo e Desafiador}

A educação também tem sido estudada como um sistema complexo. Por exemplo, o sistema educacional pode ser descrito como um sistema complexo, em que os agentes (alunos, professores, dirigentes) são indivíduos que interagem por meio de interações sociais específicas (links) como comunicação (aulas, palestras), interação por pares, interação socioemocional, etc. Os estados ' $\sigma_{i}$ ', referentes às pessoas $i$, poderiam incluir o nível social, saúde, gênero, raça, religião, etc. É claro que as interações $(\mathrm{M})$ dos alunos entre si e com os outros agentes vão determinar ou, pelo menos, influenciar sua aprendizagem [16].

A visão da educação como um sistema complexo pode trazer inúmeros benefícios para a pesquisa em educação e para políticas educacionais. A ideia consiste em métodos de modelagem computaciona ${ }^{12}$ da teoria da complexidade, em complementação a métodos quantitativos e qualitativos com cada método dando insights sobre a dinâmica da questão do sistema educacional em estudo, e ao mesmo tempo, permitindo uma análise em conjunto, como sugerido no diagrama da Figura 7 [35.

Bernard Ricca discute abordagens da teoria da complexidade para ensino e a formação de professores que, segundo o autor, superam os métodos usuais de ensino 36.

Forsman et al. estudaram a retenção de alunos de física e de engenharia de uma universidade tradicional sueca, usando o pensamento da complexidade e

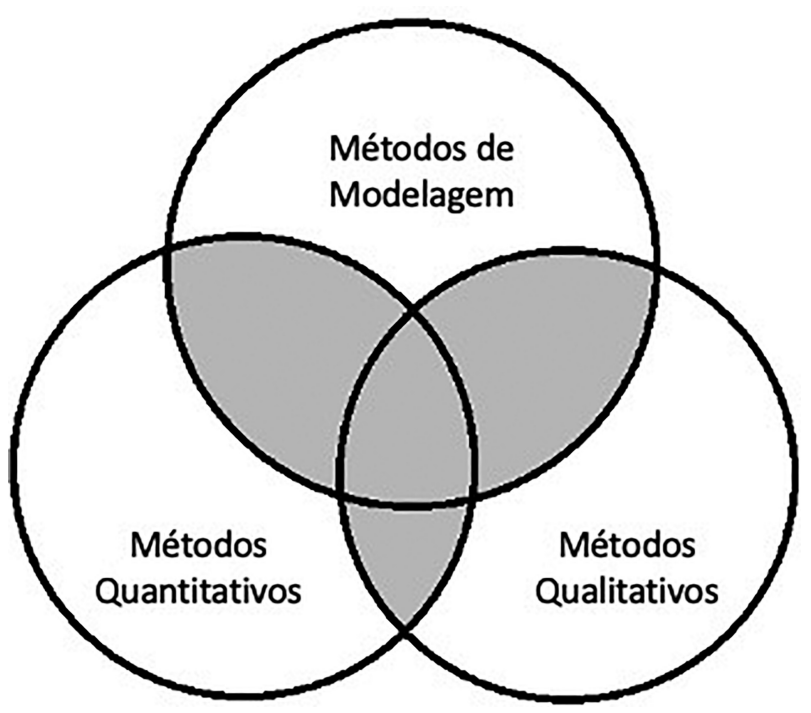

Figura 7: Áreas distintas e de sobreposição dos métodos de modelagem, quantitativos e qualitativos a serem trabalhados na análise de uma questão do sistema educacional. Adaptado da Ref. [35].

12 São usados modelos baseados em agentes (ABMs na sigla em inglês). 


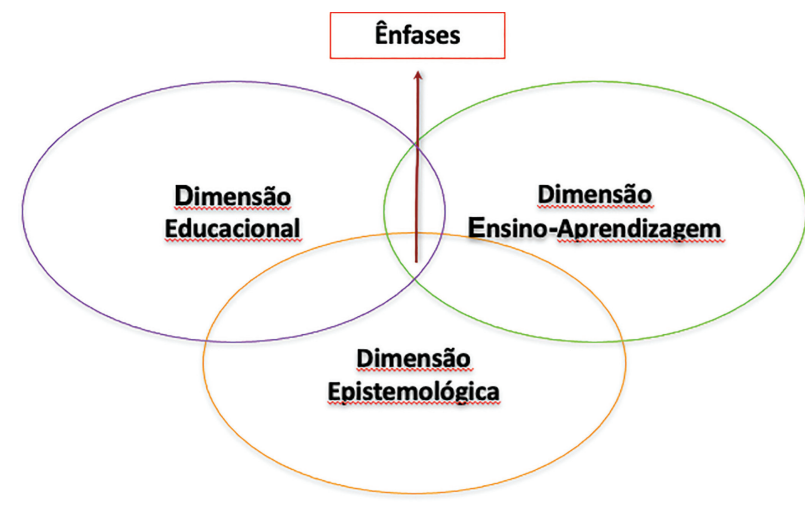

Figura 8: Consideração das Dimensões e Ênfases (dinâmica, temporal, entrópica e inter-relações) como elementos orientadores da perspectiva da complexidade. Fonte: Watanabe (artigo nessa edição).

estenderam em outro artigo discussão sobre aspectos da complexidade, trazendo, entre outras, uma análise dos aspectos estruturais das networks de interações dos alunos como uma dinâmica importante na persistência do aluno 37, 38.

No Brasil, a complexidade no contexto educacional nasceu como crítica à simplificação. Ou seja, em oposição à fragmentação do conhecimento na aprendizagem, na formação de professores, e na elaboração dos currículos. A teoria dos sistemas complexos, como discutida aqui, não chegou às escolas. A proposta educacional de complexidade no contexto brasileiro tem sido fortemente influenciada pela perspectiva do filósofo e sociólogo Edgar Morin [39].

\section{- Complexidade no Ensino de Física}

Nesta edição, Giselle Watanabe destaca a sua pesquisa sobre alguns aspectos da complexidade presentes em três dimensões: Educacional (formação do indivíduo); Ensino-Aprendizagem (contexto da sala de aula); Epistemológica (abordagem de situações longe do equilíbrio e dinâmicas) como exibido na Figura 8 . Nesse sentido, buscam-se os aspectos da complexidade que têm significado para os docentes e seus alunos no processo de construção do conhecimento escolar. Ao final, Watanabe dá exemplo de como complexidade pode ser trabalhada na sala de aula por meio de uma proposta de discussão de questões socioambientais, pautadas nos conceitos da Física e na temática das emergências climáticas.

\section{- Sistema climático e corpo humano}

Na mesma direção, Diogo de Magalhães e Frederico Cruz tecem considerações didáticas sobre conceitos de complexidade para o ensino da Física de sistemas complexos. As discussões dos autores são baseadas em questões do aquecimento global e em uma analogia do sistema climático com corpo humano (dois sistemas complexos), utilizando o conceito de temperatura como pano de fundo para suas reflexões.

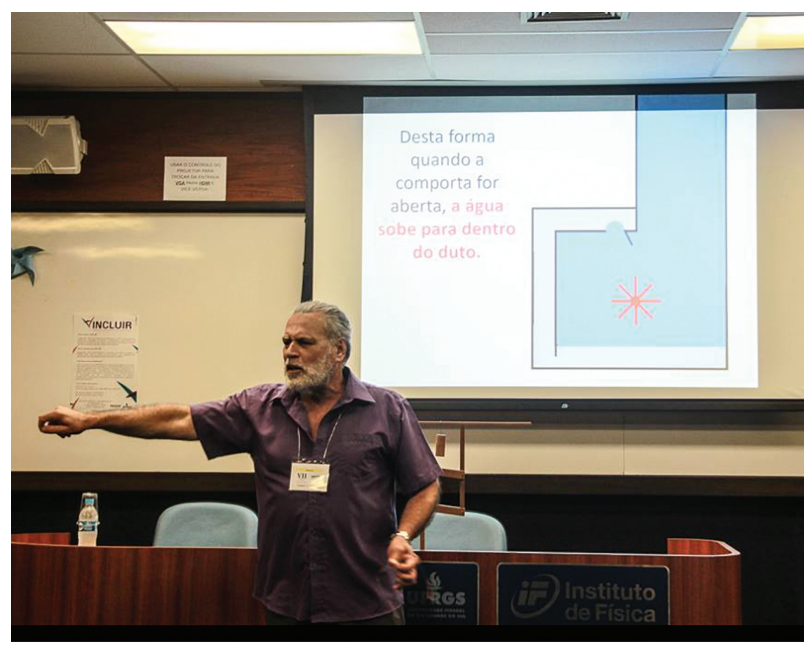

Figura 9: Professor Lang apresenta postagens polêmicas em Encontro de Ensino (2017).

Em particular, Magalhães e Cruz analisam críticas negacionistas improcedentes acerca do aumento da temperatura global da Terra. Ao avaliar a evolução da temperatura da Terra ao longo de sua história geológica, enfatizam conceitos intrínsecos aos sistemas complexos que podem ser aplicados no contexto escolar, como a não linearidade e a emergência. Aliás, outro aspecto interessante do artigo é que os autores enfatizam como os modelos climáticos buscam considerar as complexidades do sistema climático, o que evidencia o papel central dos modelos na investigação científica, algo que precisa ser mais enfatizado com os estudantes.

\section{- Pergunte ao CREF}

Essa edição comemora os dez anos do portal "Pergunte ao CREF" desenvolvido pelo Centro de Referência para o Ensino da Física (CREF) do IF-UFRGS que tem tido considerável impacto junto a alunos e professores. A finalidade principal do portal não é ensinar física básica de forma tradicional. Contudo, ao responder questões de um público curioso e interessado em aprender, o responsável pelo portal, Fernando Lang da Silveira, (Figura 9, autor do artigo, responde de forma simples e detalhada questões complicadas, polêmicas ou simplesmente curiosas, corrige mitos da ciência e concepções equivocadas sobre Física e ciências afins. O artigo descreve números do portal e comenta sobre as postagens mais acessadas.

\section{- Neurociência e pesquisas de Ensino}

Neuroeducação é uma área emergente que abrange três sistemas complexos: mente, cérebro e educação. Guilherme Brockington defende no artigo dessa edição, o potencial de uso do arcabouço teórico-metodológico das ciências do cérebro para as pesquisas em ensino de ciências. Após tecer considerações sobre a relação da neurociência com a aprendizagem e de que modo o cérebro reage a conteúdos de Matemática e de Física, 

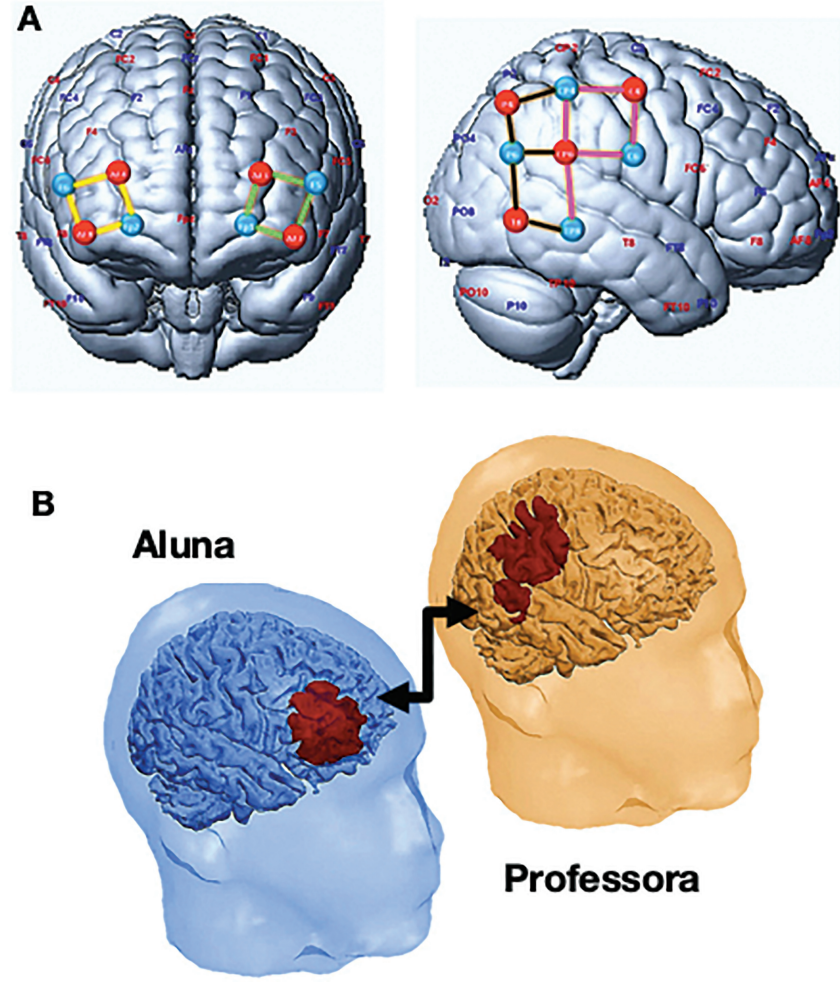

Figura 10: (A). llustração de fontes (vermelho), detetores (azul) e canais agrupados em quatro regiões cerebrais: córtex frontal esquerdo (verde) e direito (amarelo), junção tempoparietal anterior (rosa) e posterior (marrom); (B) Correlação interencéfalo significativa aluna-professora. Fonte: Brockington (artigo nessa edição).

Brockington descreve várias pesquisas seminais sobre o uso de neuroimagem de interesse para o Ensino da Física com destaque para a persistência de concepções alternativas de alunos de física e a ansiedade gerada por conteúdos das disciplinas de STEM (sigla em inglês para Science, Technology, Engineering and Mathematics).

$\mathrm{O}$ artigo apresenta resultados de pesquisa, coordenada pelo autor, na qual foi realizado teste de conceito com dados coletados de um aluno na simulação de uma aula real de Física. Foi utilizado o eye-tracking juntamente com a técnica fNIRS (sigla em inglês para Functional Near Infrared Spectroscopy). Foi obtido, entre outros resultados, o alinhamento da atividade neural da professora e da aluna durante o processo de ensino e aprendizagem. A Figura 10 ilustra os resultados da experiência. Outra experiência desenvolvida consistiu na medição das atividades cerebrais de 4 estudantes em aula expositiva. Ficou evidenciada a diminuição com o tempo da atenção e nível de excitação dos alunos, um resultado que tem sido observado empiricamente em sala de aula.

\footnotetext{
$\overline{13}$ Instrumento que capta o reflexo de infravermelho próximo nos olhos, permitindo o rastreamento ocular e, desse modo, detectar onde a pessoa coloca sua atenção, a posição de seus olhos e o tamanho da pupila.
}

\section{- Desafios no Ensino de Física}

Há vinte anos, Marco A. Moreira [40], a convite do Editor, fez uma breve retrospectiva do Ensino de Física no Brasil e apontou a necessidade de profunda reformulação curricular tanto no nível médio como no superior com foco em dois documentos que forneceram importantes subsídios para tal reformulação: as Diretrizes Curriculares para os Cursos de Graduação e os Parâmetros Curriculares Nacionais para o Ensino Médio. É bem conhecido que esses documentos foram revogados por novas diretrizes do MEC. Atualmente, os cursos de graduação (Bacharelado e Licenciatura) em Física seguem legislações específicas. No nível médio, a reestruturação foi mais profunda com a edição da lei do "Novo Ensino Médio" (2017) e as disciplinas de Física, Química e Biologia foram integradas na área de Ciências da Natureza. A Base Nacional Curricular Comum é um documento normativo para a elaboração dos currículos escolares em todos os níveis da Educação Básica. Sua implementação no nível médio está sendo feita com certa relutância, em especial pela introdução dos "itinerários formativos". Infelizmente as dificuldades enfrentadas para a melhoria do ensino não se limitam a questões curriculares, haja vista que são encontrados na ensinagem (processo indissociável de ensinar e aprender) problemas e soluções extremamente complexos.

Nessa edição, Moreira não foca em currículos. Discute questões que, embora conhecidas, não estão presentes no atual ensino e que constituem desafios a serem enfrentados. Defende que a ensinagem de Física de envolver "conceitos e conceitualização, modelos e modelagem, atividades experimentais, competências científicas, situações que façam sentido, aprendizagem significativa, dialogicidade e criticidade." Em essência, elabora respostas para uma questão crucial: Como despertar nos alunos o interesse pela Física?

\section{Complexidade Computacional}

\section{- Bósons e Férmions sob a Perspectiva da Complexidade Computacional}

$\mathrm{O}$ artigo de Daniel Brod visa "explorar as conexões conceitualmente ricas e tecnologicamente úteis entre a dinâmica de partículas quânticas livres e a teoria da complexidade".

De início, esse artigo considera apenas transformações correspondentes à Óptica linear. Usando o formalismo de segunda quantização, o autor determina a probabilidade de transição entre os estados de entrada e saída, enfatizando como a diferença nas expressões para bósons e férmions decorre apenas das relações de comutação e anticomutação. A generalização dessas probabilidades para sistemas maiores pode ser formulada em termos de funções matriciais conhecidas, o determinante (férmions) e o permanente (bósons). O artigo descreve, então, as classes de complexidade $\mathrm{P}$ e NP, \#P e a hierarquia polinomial, e as relações entre elas. $\mathrm{O}$ autor mostra 
como o determinante e o permanente - e, portanto, as probabilidades de transição nos sistemas de bósons e férmions livres - se inserem nessa classificação e como isso evidencia uma grande diferença em sua complexidade computacional.

O objetivo é, então, elaborar uma tarefa computacional concreta que, em princípio, possa ser realizada experimentalmente usando amostragem de férmions ou bósons após uma evolução de Óptica linear, e comparar seu desempenho com aquele de um computador clássico que executa a mesma tarefa. Mostra-se que o grau de complexidade desta tarefa é muito maior para bósons do que férmions. O fato de que a Óptica linear bosônica, ao contrário da fermiônica, não pode ser simulada de forma eficiente em um computador clássico leva naturalmente a um experimento muito simples para demonstrar o conceito de vantagem (ou supremacia) computacional quântica.

Assim, os dois sistemas que o autor considera, formados por bósons ou férmions não interagentes, podem ser vistos como tipos rudimentares de computadores quânticos que diferem radicalmente em suas potencialidades computacionais.

Passando para o problema mais geral de bósons e férmions interagentes, Brod mostra que há uma inversão de complexidade. Se a tarefa é, por exemplo, calcular a energia do estado fundamental, sistemas fermiônicos tendem a ser muito mais difíceis de resolver do que os bosônicos 14

Concluindo, o artigo é um convite atraente para que estudantes de pós-graduação e pesquisadores de outras áreas se familiarizem com noções fundamentais desse fascinante campo, de crescente desenvolvimento, da computação quântica.

\section{- Neurociência computacional}

O artigo do grupo de Antonio Roque traz uma breve introdução da neurociência teórica que permite ao leitor da área de Física se familiarizar com o tema. Um dos desafios da área é modelar a emergência de estados espontâneos síncronos e assíncronos a partir de uma mesma rede de neurônios de disparos. Os modelos de neurônios da classe denominada integra-e-dispara são os modelos de neurônio mais simples utilizados em neurociência teórica. Tais modelos consideram diferentes estruturas de rede e dinâmicas sinápticas. Mostra-se que comportamentos complexos similares aos estados espontâneos observados no neocórtex podem emergir em modelos de redes neuronais compostos por elementos com dinâmica simples.

\section{- Modelagem da Ciência}

Esse interessante e lúcido artigo usa modelagem computacional para investigar a influência da complexidade do

\footnotetext{
14 É bem conhecido o problema do "sinal menos" nas simulações de Monte Carlo de sistemas fermiônicos.
}

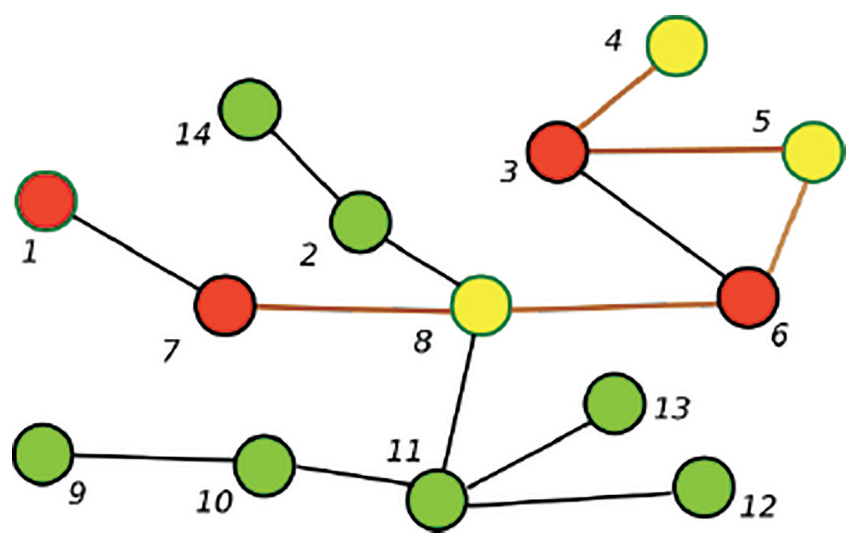

Figura 11: Rede do conhecimento com as sub-redes de nós (em vermelho), representam a parte conhecida do conhecimento, os vizinhos próximos (em amarelo) e as ligações (laranja). Fonte: Costa (artigo nessa edição)

conhecimento sobre o respectivo potencial de progresso científico.

Luciano Costa foca na questão de como a complexidade topológica da rede de conhecimento pode influenciar as potencialidades de progresso do conhecimento.

Ele parte da ideia de que todo corpo de conhecimento pode ser representado por uma rede complexa em que cada nó representa uma porção de conhecimento enquanto as interconexões expressam inter-relações entre essas partes do conhecimento. A descrição do problema está ilustrada na Figura 11. Os núcleos, (nós vermelhos) representam a parte conhecida atualmente de toda a rede de $N(=14)$ nós. A quantificação do potencial de descoberta é dada por tais configurações em termos do número de modos $n$ e ligações $e$ ainda não conhecidas que estão próximas ao núcleo (em amarelo) e que, então, podem ser descobertas a partir das ligações (em laranja) com os núcleos. Especificamente, a razão $r=n / N$ é tomada como a indicação relativa do potencial de avanço científico e a sua eficiência é dada por $s=n / e$. Neste exemplo, $r=3 / 14$ e $s=3 / 15$.

A questão que se coloca é como o potencial de descoberta científica depende da complexidade da rede de conhecimento e do núcleo.

Foram usados dois modelos de redes complexas, um mais simples e outro mais complexo, e os resultados surpreendentemente apontam que a "complexidade da rede de conhecimento pode ter pouco efeito sobre o potencial de avanço científico conforme modelado na presente abordagem."

\section{Agradecimentos}

Aos autores e autoras que gentilmente aceitaram contribuir nessa edição especial da RBEF pela disponibilidade e pela excelente qualidade dos artigos. Ao Editor, Silvio Salinas, pelo apoio e leitura crítica desse artigo. 


\section{Material suplementar}

O seguinte material suplementar está disponível online: Texto Suplementar ao artigo: Complexidade na Física e seu Ensino (Studart).

\section{Referências}

[1] R. Poli, Cadmus 2, 142 (2013).

[2] M. Mitchell, Complexity: A guide tour (Oxford University Press, Oxford, 2011).

[3] G. Parisi, Physica A 263, 557 (1999).

[4] D. Ruelle, Acaso e Caos (Editora Unesp, São Paulo, 1991).

[5] F. Lang, Caderno Brasileiro de Ensino de Física 10, 137 (1993).

[6] R.A. Vasconcellos, C.G. Rodrigues e R. Luzzi, Revista Brasileira de Ensino de Física 37, 2314 (2015).

[7] M. Marković e C. Gros, Physics Reports 536, 41 (2014).

[8] I. Gleria, R. Matsushita e S. Silva, Revista Brasileira de Ensino de Física 26, 99 (2004).

[9] D. Sherrington, Philosophical Transactions of Royal Society A 368, 1175 (2010).

[10] S. Thurner, R. Hanel e P. Klimek, Introduction to the Theory of Complex Systems (Oxford University Press, Oxford, 2018).

[11] A. Zylbersztajn, Revista Brasileira de Ensino de Física 25, 1 (2003).

[12] P.W. Anderson, Science 177, 393 (1972).

[13] P. Coleman, em: The Routledge Handbook of Emergence, editado por S. Gibb, R. Hendry e T. Lancaster (Routledge \& CRC Press, Londres, 2018).

[14] P.W. Anderson, More and Different (World Scientific, Singapura, 2011).

[15] M. Martínez, E. García e C. Bernal, Scientiæ Studia 15, $243(2017)$

[16] Y. Holovatch, R. Kenna e S. Thurner, European Journal of Physics 38, 023002 (2017).

[17] H. Poincaré, em: Henri Poincaré: Ensaios Fundamentais, editado por A.A.P. Videira e I.C. Moreira (Contraponto, Rio de Janeiro, 2008).

[18] D. Ruelle, Complexity 3, 26 (1997).

[19] W. Hayes, Nature Phys 3, 689 (2007).

[20] M. Cattani, I.L. Caldas, S.L. Souza e K.C. Iarosz, Revista Brasileira de Ensino de Física 39, e1309 (2017).

[21] M.C. Gutzwiller, Scientific American, 78 (1992). Disponível em https://www.scientificamerican.com/article /quantum-chaos-subatomic-worlds/

[22] M. Porter, arXiv:nlin/0107039.

[23] M.A.M Aguiar, Revista Brasileira de Ensino de Física 27, 101 (2005).

[24] L. Kouwenhoven e C. Marcus, Physics World, 35 (1998).

[25] J. Schmidt, M.R.G. Marques, S. Botti e M.A.L. Marques, npj Computational Materials 5, 83 (2019).

[26] Y. Tang, J. Kurths, W. Lin, E. Ott e L. Kocarev, Chaos 30, 063151 (2020).

[27] A.R. Studart, Advanced Materials 24, 5024 (2012).

[28] R. Weinkamer, M.A. Hartmann, Y. Brechet e P. Fratzl, Physical Review Letters 93, 228102 (2004).
[29] T. Yoshizawa, R.S. Nozawa, T.Z. Jia, T. Saio e E. Mori, Biophysical Reviews 12, 519 (2020).

[30] T. Tomé e M.J. Oliveira, Revista Brasileira de Ensino de Física 42, e20200259 (2020).

[31] D. Kaiser, How the Hippies Saved Physics (W.W. Norton \& Company, New York, 2011).

[32] C. Tsallis, Journal of Statistical Mechanics 52, 479 (1988).

[33] C. Tsallis, Brazilian Journal of Physics 39, 337 (2009).

[34] L. Phillips, Turbulence, the oldest unsolved problem in physics, disponível em: https://arstechnica.com/scienc e/2018/10/turbulence-the-oldest-unsolved-problem-inphysics/

[35] M.J. Jacobson, J.A. Levin e M. Kapur, Educational Researcher, 48, 118 (2019).

[36] B. Ricca, An International Journal of Complexity and Education 9, 31 (2012)

[37] J. Forsman, C. Linder, R. Moll, D. Fraser e S. Andersson, Studies in Higher Education 39, 68 (2014).

[38] J. Forsman, R. Moll e C. Linder, Physical Review Physics Education Research 10, 020122 (2014).

[39] E. Morin, Introdução ao pensamento complexo (Editora Sulina, Porto Alegre, 2015), $5^{\mathrm{a}}$ ed. 